\title{
Hydroureteronephrosis in women with pelvic organ prolapse: a prospective cohort study
}

\author{
Pushplata Kumari, Emily Divya Ebenezer, Caroline Salomi, \\ Vaibhav Londhe, Aruna Nitin Kekre*
}

Department of Obstetrics and Gynecology, Christian Medical College, Vellore, Tamil Nadu, India

Received: 28 June 2018

Accepted: 26 July 2018

\section{*Correspondence:}

Dr. Aruna Nitin Kekre,

E-mail: ankekre@gmail.com

Copyright: ( $)$ the author(s), publisher and licensee Medip Academy. This is an open-access article distributed under the terms of the Creative Commons Attribution Non-Commercial License, which permits unrestricted non-commercial use, distribution, and reproduction in any medium, provided the original work is properly cited.

\begin{abstract}
Background: Pelvic organ prolapses (POP) is a common problem in women. The prevalence of POP increase with age. The true prevalence and risk factor for developing hydroureteronephrosis (HUN) in women with pelvic organ prolapse is still unclear due to lack of prospective studies on sufficiently large cohorts. This prospective study was done to study the prevalence of HUN in women with POP and to identify the risk factors for developing HUN.

Methods: In this prospective observational study 219 patients were recruited for surgical repair for pelvic organ prolapse for 2 years. Preoperatively, all patients had transabdominal scan to assess the uterus, adnexa and to look for Hydroureteronephrosis (HUN). Women with presence of HUN were followed postoperatively look for the resolution of HUN.

Results: The prevalence of bilateral HUN was $6.85 \%$. The mean age of women with HUN ranged from 51-69 years. Diabetes and hypertension were significant risk factor for development of HUN (OR 4.70, 95\% CI -1.59-13.88 and OR 3.72, 95\% CI- 1.23-11.1 respectively). There was a statistically significant correlation between chronic kidney disease and HUN. (OR 1 with 95\%: CI 9.49-30.42). The correlation between stage of pelvic organ prolapse and HUN was not statistically significant $(\mathrm{p}=0.062)$. There was a statistically significant correlation between the duration (2years -15 years) of POP to HUN. (OR 0.233, 95\%0.13-0.419). Patients were followed up post operatively for resolution of HUN. HUN resolved in 9 women $(60 \%)$ and persisted in $6(40 \%)$.

Conclusions: The prevalence of bilateral HUN in women with pelvic organ prolapse was $6.8 \%$. Presence of hypertension, diabetes and chronic kidney disease was a risk factor for HUN. HUN resolved in $60 \%$ of women after pelvic reconstructive surgery.
\end{abstract}

Keywords: Hydroureteronephrosis, Pelvic organ prolapse, POP-Q

\section{INTRODUCTION}

Pelvic organ prolapses (POP) is protrusion of pelvic organs (bladder, uterus, rectum) through the vagina from its normal position. The prevalence of POP in the general population is about $37 \%$ which increases to $64.8 \%$ in older women. ${ }^{1}$ Among them at least $30 \%$ may require surgery. The reported prevalence of hydroureteronephrosis (HUN) in women with pelvic organ prolapse is 7-50\%. However, the true prevalence still unclear due to lack of prospective studies on sufficiently large cohorts.

POP interferes with daily activity of a woman's life because of symptoms related to lower urogenital and gastrointestinal tract. In 1930s, the association of fatal uremia with complete prolapse of uterus was recognized by Frank RT et al. ${ }^{2}$ Following that there have been 
multiple studies that have described the association of HUN with POP. ${ }^{3,4}$ However, there is insufficient data on the prevalence and risk factor for development of HUN in POP due to lack of well-designed prospective cohort study with appropriately large sample.

The pathophysiology behind the development of HUN in pelvic organ prolapse is well understood. However, the factors which predict the development of HUN and persistence after surgery for prolapse still remain unclear. This study has looked at the prevalence of HUN and the clinical profile of women who have undergone surgical repair for pelvic organ prolapse. Authors have also studied the risk factors for development of HUN in women with POP.

This prospective study was done to study the prevalence and risk factors for HUN in patients with pelvic organ prolapse and to follow up these patients for the resolution of HUN after pelvic reconstructive surgery.

\section{METHODS}

This is a prospective cohort study done at Christian Medical College Hospital Vellore India from January 2012 to March 2014. The study was approved by the IRB and the Ethics committee. Study group was patients with pelvic organ prolapse who are planned for pelvic reconstructive surgery. Women with POP who were planned for vaginal hysterectomy with pelvic floor repair were included after obtaining an informed consent.

The clinical details of the patients including the age, parity, duration, stage of prolapse and associated comorbidities like Hypertension, Diabetes mellitus, chronic kidney disease were noted. Type and degree of prolapse was staged according to the standard Pelvic organ Prolapse-Quantification (POP-Q) system by the International Continence Society. ${ }^{5}$

Transabdominal ultrasonography was performed in all the patient to assess the back-pressure changes in the kidney after emptying the bladder. Measurement of the maximum length of both the kidneys were taken in the coronal plane and the size of dilatation of bilateral renal pelvis in the transverse plane. HUN was defined as distention of the renal calyces and pelvis with urine as a result of obstruction of the outflow of urine distal to the renal pelvis. Degree of HUN was graded as mild, moderate and severe as described by Martin I et al. ${ }^{6}$ Mild HUN is mild separation of the central sinus echo complex by tubular anechoic urine filled-renal pelvis and calyces. Moderate HUN is a definite anechoic separation of the entire renal sinus, which is easily seen to extend into the calyces. Severe HUN is marked dilatation of the collecting system with parenchymal thinning.

All patients underwent vaginal Hysterectomy with pelvic floor repair. Patient with pre-operative.
Hydroureteronephrosis were followed up at 3, 6 and 12 months after surgery for resolution of HUN.

\section{Statistical analysis}

Measured outcome was the prevalence of bilateral HUN in women with POP. Chi square and Fisher's exact test were used to finding out the significance. $P$ value of $<0.05$ was considered significant. Multivariate logistic regression analysis was used to determine the association between the different risk factors and presence or absence of HUN. Data was coded and stored in Microsoft excel 2000 and analyzed with SPSS statistical program.

\section{RESULTS}

Over the period of 2 years, 219 women with Pelvic organ prolapse underwent vaginal hystrectomy with pelvic reconstructive surgery. The median age of the women was 50 years (range 40-60 years). $76.4 \% \quad(n=156)$ of women had stage 3 POP while and $23.53 \%(n=48)$ had stage 4 POP.

Preoperative ultrasound was done in all patients for the evidence of HUN. Bilateral HUN was seen in women with stage 3 and 4 POP. Out of 219 patients, Bilateral HUN was present in 15 women giving a prevalence of $6.85 \%$. According to the grades of HUN, 7 patients had mild and 8 patients had moderate degree of HUN.

Table 1: Demographic characters of the patients.

\begin{tabular}{|llll|}
\hline $\begin{array}{l}\text { Demography } \\
\text { Age (in years) }\end{array}$ & $\begin{array}{l}\text { WUN* } \\
(\mathbf{n}=15)\end{array}$ & $\begin{array}{l}\text { Without HUN } \\
(\mathbf{n}-=204)\end{array}$ & $\begin{array}{l}\text { p } \\
\text { value }\end{array}$ \\
\hline$<40$ & $2(13.33 \%)$ & $70(34.31 \%)$ & \\
\hline $40-59$ & $7(46.67 \%)$ & $91(44.61 \%)$ & \\
\hline$>60$ & $6(40 \%)$ & $43(21.08 \%)$ & \\
\hline $\begin{array}{l}\text { Diabetes } \\
\text { mellitus }\end{array}$ & $7(46.67 \%)$ & $32(16.89 \%)$ & 0.007 \\
\hline Hypertension & $6(40 \%)$ & $31(15.2 \%)$ & 0.024 \\
\hline $\begin{array}{l}\text { Chronic kidney } \\
\text { disease }\end{array}$ & $3(20 \%)$ & Nil & 0.000 \\
\hline POP\# stage & & & 0.062 \\
\hline $\begin{array}{l}\text { Stage 2 } \\
\text { Stage 3 }\end{array}$ & $8(53.33 \%)$ & $137(67.2 \%)$ & \\
\hline Stage 4 & $7(46.67 \%)$ & $48(23.5 \%)$ & \\
\hline Duration of POP & 8 & 12 & 0.000 \\
\hline$<5$ years & 3 & 122 & \\
\hline 5-15 years & 4 & 70 & \\
\hline 15 years & & & \\
\hline
\end{tabular}

*HUN- hydroureteronephrosis, "POP- pelvic organ prolapse

Of the 219 women with POP 204 patients did not have HUN. $34.31 \%(n=70)$ patients were between 40-49years of age, $44.61 \%(n=91)$ were between $50-59$ years and $21.08 \%(n=43)$ were more than 60 years of age. The prevalence of HUN was $2.8 \%, 7.1 \%$ and $12.2 \%$ among women in these three age groups. The duration of prolapse in these patients ranged from 2 years to 15 
years. Diabetes mellitus and hypertension were found in $16.89 \%(\mathrm{n}=32)$ and $15.2 \%(\mathrm{n}=31)$ patients respectively. (Table 1).

The backward logistic regression analysis was performed to assess the impact of 5 factors (age, diabetes mellitus, and hypertension, stages and duration of POPP) in the development of HUN. Age, hypertension and duration of prolapse had a trend toward increased risk but were not statistically significant. Diabetes and stage of POP were significant risk factors for development of HUN (OR $3.74395 \%$ CI: $1.093-12.825$, p value 0.036 and OR 3.130 95\% CI: $1.045-9.372 \mathrm{p}$ value 0.041 respectively) (Table 2).

Table 2: Logistic regression analysis of $\mathrm{HUN}^{*}$ and related factors.

\begin{tabular}{|c|c|c|c|}
\hline Variables & $\begin{array}{l}\text { Odds } \\
\text { ratio }\end{array}$ & $\begin{array}{l}95 \% \\
\text { confidence } \\
\text { interval }\end{array}$ & $\begin{array}{l}p \\
\text { value }\end{array}$ \\
\hline Age & 1.181 & $0.472-2.953$ & 0.722 \\
\hline Diabetes mellitus & 3.743 & $1.093-12.825$ & 0.036 \\
\hline Hypertension & 1.542 & $0.384-6.196$ & 0.542 \\
\hline Stage of $\mathrm{POP}^{\#}$ & 3.130 & $1.045-9.372$ & 0.041 \\
\hline Duration of POP & 1.839 & $0.580-5.835$ & 0.301 \\
\hline
\end{tabular}

Among the 15 patients with bilateral HUN, $13.33 \%(n=2)$ patients were between $40-49$ years of age, $46.67 \%(n=7)$ patients were between 50-59 years of age and $40 \%(n=6)$ patients were more than 60 years of age. Diabetes, hypertension and chronic kidney disease were found in 7 (46.67\%), $6(40 \%)$ and $3(20 \%)$ patients respectively. Eight $(53.3 \%)$ patient had stage 3 POP whereas seven $(46.67 \%)$ of them had stage 4 prolapse (Table 3 ).

Table 3: Characteristics of the patient with HUN that has either persisted or resolved.

\begin{tabular}{|c|c|c|c|}
\hline Demography & $\begin{array}{l}\text { HUN* } \\
\text { Persisted }\end{array}$ & $\begin{array}{l}\text { HUN } \\
\text { Resolved }\end{array}$ & $\begin{array}{l}\text { p- } \\
\text { value }\end{array}$ \\
\hline Age (in years) & & & 0.897 \\
\hline$<40$ & $1(16.7 \%)$ & $1(11.1 \%)$ & \\
\hline $40-59$ & $3(50 \%)$ & $4(44.4 \%)$ & \\
\hline$>60$ & $2(33.3 \%)$ & $4(44.4 \%)$ & \\
\hline Diabetes mellitus & $1(16.7 \%)$ & $6(66.7 \%)$ & 0.119 \\
\hline Hypertension & $2(33.3 \%)$ & $4(44.4 \%)$ & 1 \\
\hline $\begin{array}{l}\text { Chronic kidney } \\
\text { disease }\end{array}$ & 0 & $3(33.3 \%)$ & 0.229 \\
\hline POP $^{\#}$ stage & & & 0.608 \\
\hline Stage 1 & 0 & 0 & \\
\hline Stage 2 & 0 & 0 & \\
\hline Stage 3 & $4(66.7 \%)$ & $4(44.4 \%)$ & \\
\hline Stage 4 & $2(33.3 \%)$ & $5(55.6 \%)$ & \\
\hline Duration of POP & & & 0.060 \\
\hline$<5$ years & $1(16.7 \%)$ & $3(33.3 \%)$ & \\
\hline $5-15$ years & $3(50 \%)$ & 0 & \\
\hline 15 years & $2(33.3 \%)$ & $6(66.7 \%)$ & \\
\hline
\end{tabular}

All 15 women with HUN were followed up after pelvic reconstruction surgery for resolution of the same at 3, 6 and 12 months. In $9(60 \%)$ women HUN resolved 4 (26.6\%) women with mild HUN persisted and 2 (13.3\%) loss of follow up (Figure 1).

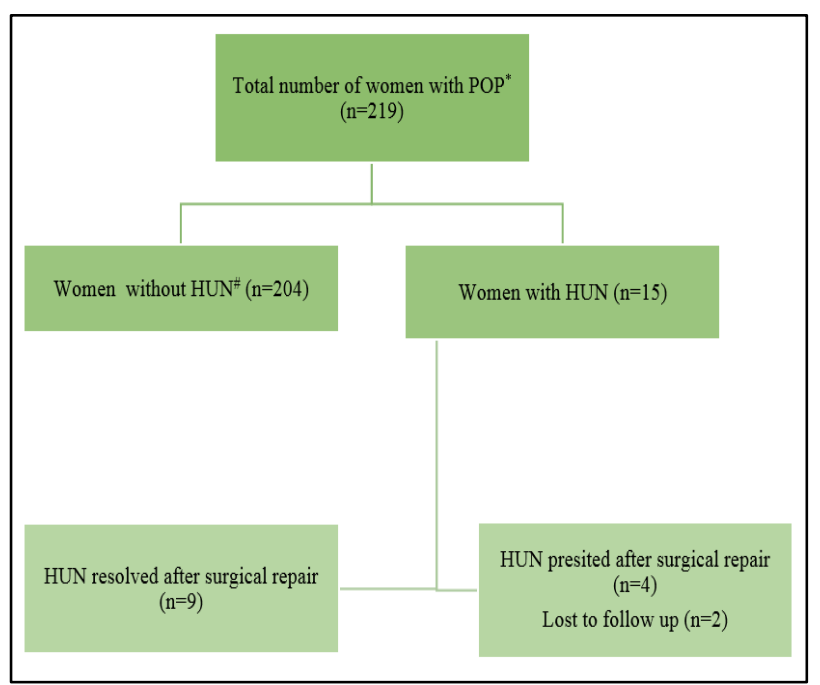

"POP- pelvic organ prolapse ${ }^{\#} \mathrm{HUN}$ - hydroureteronephrosis

Figure 1: Flow chart showing patient recruitment and the follow-up.

\section{DISCUSSION}

In this study, out of the 219 patients who presented with pelvic organ prolapse 15 patients had Hydroureteronephrosis, giving a prevalence of $6.85 \%$. The prevalence of HUN was similar to study conducted by Costantini et al and Beverly et al which were $5 \%$ and $7.7 \%$ respectively. ${ }^{7,8}$ A prospective observational study from China by Hui et al have reported a $10.3 \%$ prevalence of HUN in their study. ${ }^{9}$ While in a study by Dancz et al the prevalence was $30.6 \% .^{10}$

Seven women in this study had mild HUN and eight had moderate HUN. In study by Beverly et al majority of the women ( 22 out of 25 women) had mild and moderate HUN. ${ }^{8}$ However, $8(61.5 \%)$ out of 13 cases studied by Costantini et al had severe HUN. ${ }^{7}$

There was a strong correlation between age of the patient and HUN. The prevalence was $2.8 \%, 7.1 \%$ and $12.2 \%$ in age group of 40-49, 50-59 and more than 60 years respectively. Other studies also concluded that percentage of HUN is more in older women. ${ }^{7,9}$

In this study $5.5 \%$ (8 out of 145 ) women had HUN in stage 3 POP whereas $12.7 \%$ (7 out of 55) had HUN in stage 4 POP. The prevalence of HUN in study by Hui et al was $17.7 \%$ and $33.3 \%$ in stage 3 and 4 POP respectively. ${ }^{9}$ While in another prospective study by Dancz et al the prevalence of HUN in stage 3 and 4 POP was $22.2 \%$ and $63.1 \%$ respectively. ${ }^{10}$ 
The women with bilateral HUN had significantly higher prevalence of Diabetes Mellitus (46.67\% versus $16.89 \%$, $\mathrm{p}=0.007)$, Hypertension $(40 \%$ versus $15.2 \%, \mathrm{p}=0.024)$ and Chronic Kidney disease (20\% versus Nil, $\mathrm{p}=0.000)$ in comparison to women without HUN. The prevalence of diabetes mellitus (54.2\% versus $22.5 \%$; $=0.002)$ and hypertension $(70.8 \%$ versus $44.0 \% ; \mathrm{p}=0.023)$ were significantly higher in women with HUN group. ${ }^{9}$ In study by Dancz et al Diabetes mellitus $(21.1 \%$ versus $10 \%$, $\mathrm{p}=$ 0.009 ) was significantly higher in women with HUN however, hypertension was not significant $(21.8 \%$ versus $22.4 \%, \mathrm{p}=0.93) .{ }^{10}$

Out of the five factors that were used for backward logistic regression to determine the risk factors for development of HUN, diabetes mellitus and stage of POP were found to be statistically significant (OR $3.74395 \%$ CI: $1.093-12.825, \mathrm{p}$ value 0.036 and OR $3.13095 \% \mathrm{CI}$ : 1.045-9.372 $\mathrm{p}$ value 0.041respectively). Hui et al had found stage of POP as only statistically significant risk factor (OR 3.42, 95\% CI 1.29-9.06) on multiple logistic regression analysis on six risk factors. ${ }^{9}$ Dancz et al has also found the degree of prolapse (OR 1.68, 95\% CI 1.222.12) as significant risk factor after controlling for various other factors. ${ }^{10}$

Out of the 15 patients who had bilateral HUN preoperatively, HUN resolved in $9(60 \%)$ women, persisted in $4(26.6 \%)$ women and $2(13.3 \%)$ loss of follow up. In a study by Costantini et al, HUN resolved in $77.8 \%$ (7 out of 9) women after pelvic floor repair. ${ }^{7}$ The complete resolution of HUN after surgical repair was $95.2 \%$ (20 out of 21 patients, 3 lost to follow up) in study by Hui et al. ${ }^{9}$ Age of the presentation, medical morbidities (diabetes mellitus, hypertension, chronic kidney disease), stage of pelvic organ prolapse and duration of POP was not significantly difference in the two group of women whose HUN either persisted or resolved after pelvic floor repair.

\section{CONCLUSION}

The prevalence of bilateral HUN in women with POP our study was $6.85 \%$. Bilateral HUN was found in women with stage 3 and 4 POP. The statistically significant risk factor for development of HUN was diabetes mellitus and stages of POP. The complete resolution of HUN after surgery was observed in $60 \%$ of women.

\section{ACKNOWLEDGMENTS}

Authors would like to acknowledge women who are participated in this study, the doctors who cared for these women in the post-operative wards.
Funding: No funding sources

Conflict of interest: None declared

Ethical approval: The study was approved by the Institutional Ethics Committee IRB 7884 dated 27.06.2012

\section{REFERENCES}

1. Gemer O, Bergman M, Segal S. Prevalence of hydronephrosis in patients with genital prolapse. Eur J Obstet Gynecol Reprod Biol. 1999 Sep;86(1):11-3.

2. Frank RT. Fatal uremia due to complete prolapse of the uterus. Am J Obstet Gynecol. 22(2):270-2.

3. Hadar H, Meiraz D. Total uterine prolapse causing hydroureteronephrosis. Surg Gynecol Obstet. 1980 May;150(5):711-4.

4. Stabler J. Uterine prolapse and urinary tract obstruction. Br J Radiol. 1977 Jul;50(595):493-8.

5. Bump RC, Mattiasson A, Bø K, Brubaker LP, DeLancey JO, Klarskov P, et al. The standardization of terminology of female pelvic organ prolapse and pelvic floor dysfunction. Am J Obstet Gynecol. 1996 Jul;175(1):10-7.

6. Resnick M, Older R. Diagnosis of Genitourinary Disease https://www.thieme.com/booksmain/urology/product/1223-diagnosis-ofgenitourinary-disease Accessed on April 8, 2018

7. Costantini E, Lazzeri M, Mearini L, Zucchi A, Del Zingaro M, Porena M. Hydronephrosis and Pelvic Organ Prolapse. Urology. 2009 Feb;73(2):263-7.

8. Beverly CM, Walters MD, Weber AM, Piedmonte MR, Ballard LA. Prevalence of hydronephrosis in patients undergoing surgery for pelvic organ prolapse. Obstet Gynecol. 1997 Jul;90(1):37-41.

9. Hui SYA, Chan SCS, Lam SYJ, Lau TK, Chung KHT. A prospective study on the prevalence of hydronephrosis in women with pelvic organ prolapse and their outcomes after treatment. Int Urogynecology J. 2011 Dec;22(12):1529-34.

10. Dancz CE, Walker D, Thomas D, Özel B. Prevalence of hydronephrosis in women with advanced pelvic organ prolapse. Urology. 2015 Aug;86(2):250-4.

Cite this article as: Kumari $\mathrm{P}$, Ebenezer ED, Salomi C, Londhe V, Kekre AN. Hydroureteronephrosis in women with pelvic organ prolapse: a prospective cohort study. Int J Reprod Contracept Obstet Gynecol 2018;7:3664-7. 